\title{
Interactions between retroactive-interference and context-mediated treatments that impair Pavlovian conditioned responding
}

\author{
Daniel S. Wheeler and Ralph R. Miller \\ State University of New York, Binghamton, New York
}

\begin{abstract}
In Pavlovian fear conditioning, context-mediated decrements in conditioned responding (e.g., the US preexposure effect) can counteract competition between cues trained together (e.g., overshadowing). Two experiments were conducted using rats in a conditioned lick suppression preparation to determine whether contextmediated competition also counteracts competition between cues trained separately (retroactive interference, or RI). In Experiment 1, a combination of degraded contingency and RI treatments produced less of a decrement in conditioned responding than did either of those treatments alone. Experiment 2 showed that RI treatment attenuates the normally deleterious effect of trial massing. The results suggest that empirical similarities are shared by interference between cues trained apart and competition between cues trained together.
\end{abstract}

The field of Pavlovian conditioning has been concerned largely with the factors that impact the acquisition or extinction of associations that are formed between conditioned stimuli (CSs) and unconditioned stimuli (USs). These factors include variables such as CS salience, US intensity, contingency, contiguity, trial spacing, and CS duration, among others. In recent decades, many studies of Pavlovian conditioning have been conducted to investigate the ways that stimuli interact when trained together (i.e., in compound) with a common US. Compound training often results in reduced expression of the CS-US association by one or both of the CSs relative to a condition in which each of the CSs is trained alone (i.e., elementally). Overshadowing (Pavlov, 1927, pp. 142-143 and 269-270) is a classic example of this sort of cue competition in which conditioned responding to one of two CSs (typically the less salient) is reduced when the CSs are trained together relative to a situation in which that CS is trained elementally.

Research suggests that some of the factors that affect conditioned responding to an elementally trained CS have a different impact on a CS that is trained in compound with another CS. For example, when a CS is preexposed without reinforcement prior to CS-US training trials, the expression of the CS-US association is retarded in the initial trials (i.e., latent inhibition; see, e.g., Lubow $\&$ Moore, 1959). Latent inhibition is a ubiquitous effect that has been observed across many tasks and species (for reviews, see Lubow, 1989; Lubow \& Gerwitz, 1995), and at least operationally CS preexposure may be considered a reliable influence of CS-US contingency on Pavlovian conditioning. However, when a CS is trained in compound with another CS, CS preexposure does not always lead to retarded conditioned responding. In certain compound conditioning situations, CS preexposure actually attenuates the overshadowing effect that otherwise occurs as a result of compound training (Blaisdell, Bristol, Gunther, \& Miller, 1998; Loy \& Hall, 2002; but see Nakajima, Ka, \& Imada, 1999; Nakajima \& Nagaishi, 2005). In a conditioned suppression preparation with rat subjects, Blaisdell et al. observed that preexposure to a CS (X) before its reinforcement in compound with a more salient CS (A) results in conditioned responding to $\mathrm{X}$ that is stronger than that which results when $\mathrm{X}$ is not preexposed prior to compound training. Furthermore, the conditioned responding to $\mathrm{X}$ after CS preexposure and compound conditioning was stronger than it was when $\mathrm{X}$ was preexposed and then reinforced elementally. In summary, the otherwise response-degrading effects of overshadowing training (AX-US) and latent inhibition training (X- followed by X-US) seem to counteract each other when the two treatments are combined (X- followed by AX-US). The counteraction observed by Blaisdell et al. was robust to the point that responding to $\mathrm{X}$ after combined latent inhibition and overshadowing treatments appeared not to be very different from responding to $\mathrm{X}$ after it had been reinforced elementally with no nonreinforced preexposure to $\mathrm{X}$.

The results of Blaisdell et al. (1998) suggest that at least one of the factors that reliably impacts conditioned responding to an elementally trained CS can have a different effect on responding to a CS that is trained in compound with another CS. Blaisdell et al.'s pioneering work has been developed further by other researchers who investi- 
gated factors other than CS preexposure that usually have a negative impact on conditioned responding. It has been found that the effect of overshadowing treatment is attenuated by normally response-degrading treatments such as unsignaled US presentations prior to conditioning (i.e., US preexposure; Urushihara \& Miller, 2006a), interspersed unsignaled US presentations (i.e., degraded contingency [DC] treatment; Urcelay \& Miller, 2006), interspersed unreinforced CS presentations (i.e., partial reinforcement; Urushihara \& Miller, 2006b), long CS durations (Urushihara, Stout, \& Miller, 2004; Westbrook, Homewood, Horn, \& Clarke, 1983), and temporally massed training trials (Stout, Chang, \& Miller, 2003). Taken together, these results provide strong evidence of a dissociation in processing between CSs that are trained in compound and CSs that are trained elementally.

Miller and his colleagues have suggested that results such as those presented above indicate that the factors that impact conditioning can be different for elementally trained stimuli and for stimuli trained in compound (see, e.g., Urushihara et al., 2004). This broad statement is somewhat misrepresentative of Denniston, Savastano, and Miller's (2001) explicit account of the data. More specifically, they claim that two response-degrading treatments may counteract each other because the stimuli that compete with a common target are themselves subject to competition. In all of the situations described above, there are two potential cues that may compete with the target stimulus (X). The more salient overshadowing stimulus is the obvious competing cue. The context can also be viewed as a cue that competes with $\mathrm{X}$ in situations in which the context has an exceptionally strong association with the US (e.g., DC and US preexposure), the CS (e.g., CS preexposure and partial reinforcement), or both the CS and the US (e.g., situations with massed training trials). Miller and colleagues posit that, in certain situations, two cues that compete with $\mathrm{X}$ (A and the context) can essentially compete with and counteract each other, resulting in little combined competition for X. (A more detailed description of this account is included in the General Discussion.) Notably, this explanation indicates that the most important factor in the aforementioned counteraction effects is the presence of two effective competing cues that can compete with one another.

The present experiments were conducted to investigate whether competing cues would counteract each other in situations in which one of them is not presented in compound with the target cue. To address this question, DC (Experiment 1) and trial massing (Experiment 2) treatments were combined with a retroactive interference (RI) paradigm (see, e.g., Escobar, Matute, \& Miller, 2001). In this paradigm, RI is obtained when a nontarget cue (A) is paired with an outcome $(\mathrm{O})$ after a target cue $(\mathrm{X})$ is trained with the same outcome ( $\mathrm{X}-\mathrm{O}$ followed by $\mathrm{A}-\mathrm{O})$. RI is evidenced by weaker expression of the $\mathrm{X}-\mathrm{O}$ association relative to a control condition with no $\mathrm{A}-\mathrm{O}$ pairings after $\mathrm{X}-\mathrm{O}$ training. $\mathrm{A}-\mathrm{O}$ training apparently retroactively interferes with the expression of the $\mathrm{X}-\mathrm{O}$ association. Because $\mathrm{X}$ and $\mathrm{A}$ are never presented simultaneously, most models of Pavlovian conditioning do not anticipate RI.
Escobar et al. (2001) observed RI only when the outcome used during training was not an actual US. In an initial order-conditioning preparation, no RI was observed, presumably because a first-order CS tends to be resistant to reductions in conditioned responding potentially induced through indirect means, such as posttraining reinforcement of a competing CS (see, e.g., Miller \& Matute, 1996). To avoid the use of a US during training, a sensory preconditioning preparation has been used in demonstrations of RI in Pavlovian conditioning. In this preparation, $\mathrm{A}, \mathrm{X}$, and $\mathrm{O}$ are all behaviorally neutral stimuli during training. After $\mathrm{X}-\mathrm{O}$ and $\mathrm{A}-\mathrm{O}$ training, $\mathrm{O}$ is reinforced with a US. Responding to the $\mathrm{X}$ stimulus is then assessed on the basis of the assumption that any responding to $\mathrm{X}$ is dependent on the $\mathrm{X}-\mathrm{O}$ and $\mathrm{O}-\mathrm{US}$ associations. Because the impact of the O-US association is presumed to be equal between the RI treatment and the control treatment (Escobar et al., 2001), any differences in responding to X may be attributed to the expression of the $\mathrm{X}-\mathrm{O}$ association.

\section{EXPERIMENT 1}

In Experiment 1, we investigated whether or not DC treatment would interact with competition between cues trained apart (RI) in the same way that it interacts with competition between cues trained together (e.g., overshadowing; Urcelay \& Miller, 2006). A cue-outcome contingency can be degraded in two ways: Either the cue can be presented without the outcome (i.e., partial reinforcement) or the outcome can be presented without the cue. In the Pavlovian conditioning literature, the DC effect specifically refers to situations in which interspersed unsignaled US presentations among CS-US training trials result in a reduction in responding to the CS (see, e.g., Rescorla, 1968). The DC effect is observed in both first-order conditioning and sensory preconditioning (see, e.g., Gunther \& Miller, 2000) and is attenuated when the target stimulus is trained in compound with an overshadowing stimulus (Urcelay \& Miller, 2006).

Urcelay and Miller (2006) demonstrated that a target cue exposed to both overshadowing and DC treatments produced greater responding than a target cue that is exposed to either of those treatments alone. The present study incorporates Urcelay and Miller's DC manipulation with Escobar et al.'s (2001) RI paradigm. In the present study, RI was produced by training a cue (A) with an outcome (O) after the same outcome had been paired with another cue (X). The $\mathrm{RI}$ control group (Ctrl-NoDC) received $\mathrm{X}-\mathrm{O}$ pairings in Phase 1 but only exposure to the A stimulus only in Phase 2 (see Table 1). This control for interference was selected because it did not involve the presentation of any unsignaled exposures of $\mathrm{O}$. In addition to the RI treatment, half of the subjects experienced DC treatment - that is, unsignaled $\mathrm{O}$ presentations in Phases 1 and 2. The other half received no DC treatment (NoDC). After Phases 1 and 2, all the subjects experienced pairings of $\mathrm{O}$ with a footshock US in a third phase of training. Afterward, $\mathrm{X}$ was tested alone to assess the expression of the $\mathrm{X}-\mathrm{O}$ association.

Because in the DC manipulation the exposure of the outcome in the training context was intentionally varied, 
Table 1

Design of Experiment 1

\begin{tabular}{llllll}
\hline & \multicolumn{2}{c}{ Context $\mathrm{A}$} & & \multicolumn{2}{c}{ Context $\mathrm{B}$} \\
\cline { 2 - 3 } \cline { 6 - 6 } \multicolumn{1}{c}{ Group } & \multicolumn{1}{c}{ Phase 1} & \multicolumn{1}{c}{ Phase 2} & & Phase 3 & Test $\mathrm{X}$ \\
\hline Ctrl-NoDC & $8 \mathrm{X} \rightarrow \mathrm{O}$ & $8 \mathrm{~A}$ & & $8 \mathrm{O} \rightarrow \mathrm{US}$ & $\mathrm{CR}$ \\
Ctrl-DC & $8 \mathrm{X} \rightarrow \mathrm{O} / 12 \mathrm{O}$ & $8 \mathrm{~A} / 12 \mathrm{O}$ & & $8 \mathrm{O} \rightarrow \mathrm{US}$ & $\mathrm{Cr}$ \\
RI-NoDC & $8 \mathrm{X} \rightarrow \mathrm{O}$ & $8 \mathrm{~A} \rightarrow \mathrm{O}$ & & $8 \mathrm{O} \rightarrow \mathrm{US}$ & $\mathrm{Cr}$ \\
RI-DC & $8 \mathrm{X} \rightarrow \mathrm{O} / 12 \mathrm{O}$ & $8 \mathrm{~A} \rightarrow \mathrm{O} / 12 \mathrm{O}$ & & $8 \mathrm{O} \rightarrow \mathrm{US}$ & $?$ \\
\hline
\end{tabular}

Note-Ctrl, control; RI, retroactive interference; DC, degraded contingency; NoDC, no DC; X, complex tone; A, click train; O, white noise; $\mathrm{US}$, footshock; $\mathrm{CR}$, strong expected conditioned response; $\mathrm{Cr}$, moderate expected conditioned response. The question mark denotes an uncertain outcome.

we used a different context for Phase 3 and testing to avoid any differences in the excitatory value of the context during testing. If the extra $\mathrm{O}$ presentations in the $\mathrm{RI}$ and $\mathrm{DC}$ conditions caused an enhancement of the excitatory value of the test context, responding between groups could be differentially affected by summation of responding to the target cue and responding to the test context. In addition, switching the context between Phases 2 and 3 should have had the additional benefit of reducing the potential effect of latent inhibition on the outcome that can be caused by nonreinforced exposure of a stimulus before reinforcement, which could also cause differences in responding between groups in this design (see, e.g., Lovibond, Preston, \& Mackintosh, 1984).

There were two well-founded expectations for Experiment 1 . RI was expected, denoted by less conditioned suppression in Group RI-NoDC than in Group Ctrl-NoDC. Also, a DC effect was expected, with less conditioned suppression in Group Ctrl-NoDC than in Group Ctrl-DC. Of critical interest was whether the two combined treatments (RI-DC) would produce more or less conditioned suppression than either treatment alone (RI-NoDC or Ctrl-DC). Intuitively, summation of response-degrading treatments might be expected. However, considering the research discussed above, it was possible that DC treatment would counteract RI and vice versa.

\section{Method}

\section{Subjects}

The subjects were 24 male (279-341 g) and 24 female (195250 g) experimentally naive Sprague Dawley descended rats obtained from our own breeding colony. The subjects were randomly assigned to one of four groups $(n \mathrm{~s}=12)$, counterbalanced within groups for sex. The animals were individually housed in standard hanging stainless steel wire-mesh cages in a vivarium maintained on a 16:8-h light:dark cycle. Experimental manipulations occurred near the middle portion of the light phase. The animals received free access to Purina Lab Chow, whereas water availability was limited to $20 \mathrm{~min}$ per day following a progressive deprivation schedule initiated 1 week prior to the start of the study. From the time of weaning until the start of the study, all the animals were handled for $30 \mathrm{sec}$ three times per week.

\section{Apparatus}

Two types of enclosures, $\mathrm{R}$ and $\mathrm{V}$, were used as Contexts A and $\mathrm{B}$ (counterbalanced). Acclimation, Phase 3, reacclimation, and testing took place in Context B, whereas Phases 1 and 2 took place in Context A. Enclosure R was a clear Plexiglas chamber in the shape of a rectangular box measuring $22.75 \times 8.25 \times 13.0 \mathrm{~cm}$ with a floor constructed of 0.48 -cm-diameter rods $1.5 \mathrm{~cm}$ apart center to center, connected by NE-2 neon bulbs, which allowed constant-current footshock to be delivered by means of a high-voltage AC circuit in series with a 1.0-M $\Omega$ resistor. Each of six copies of Enclosure R had its own environmental isolation chest. Enclosure R was dimly illuminated by a $2-\mathrm{W}$ (nominal at $120 \mathrm{VAC}$ ) incandescent bulb driven at $80 \mathrm{VAC}$ mounted on an inside wall of the environmental isolation chest approximately $30 \mathrm{~cm}$ from the animal enclosure. Background noise (primarily from a ventilation fan) was at $74 \mathrm{~dB}$ SPL (C scale).

Enclosure $\mathrm{V}$ was a $25.5-\mathrm{cm}$-long box in the shape of a truncated $\mathrm{V}$ (28 cm high, $21 \mathrm{~cm}$ wide at the top, and $5.25 \mathrm{~cm}$ wide at the bottom). Each of six copies of Enclosure V had its own environmental isolation chest. The floor and sides were constructed of sheet metal. The ceiling was clear Plexiglas. The floor consisted of two parallel metal plates, each $2 \mathrm{~cm}$ wide, with a $1.25-\mathrm{cm}$ gap between them. Enclosure V was dimly illuminated by a 7-W (nominal at 120 VAC) incandescent bulb driven at $80 \mathrm{VAC}$ mounted on an inside wall of the environmental isolation chest approximately $30 \mathrm{~cm}$ from the animal enclosure. The light entering the animal enclosure was reflected primarily from the roof of the environmental chest. Due to differences in the opaqueness of the enclosures, this level of illumination roughly matched that of Enclosure R. Background noise (primarily from a ventilation fan) was at $74 \mathrm{~dB}(\mathrm{C})$.

Each enclosure ( $R$ and $V$ ) was also equipped with three $45-\Omega$ speakers mounted on three different interior walls of each environmental isolation chest, which could deliver a complex tone ( 800 and $1000 \mathrm{~Hz}$ ) of $8 \mathrm{~dB}(\mathrm{C})$ above background, 8-dB clicks (6 sec, C), and a white noise of $8 \mathrm{~dB}(\mathrm{C})$ above the ambient background sound. In this experiment, the tone served as cue $\mathrm{X}$, the clicks served as cue $\mathrm{A}$, and the white noise served as the outcome. A and X were $30 \mathrm{sec}$ in duration, whereas $\mathrm{O}$ was $10 \mathrm{sec}$ in duration. The US was a 0.5 -sec $1.0-\mathrm{mA}$ footshock. Each enclosure was dimly illuminated by a houselight (1820 bulb). Enclosure assignments between the four groups were counterbalanced.

\section{Procedure}

Acclimation. On Day 1, all the groups were acclimated to Context $\mathrm{B}$ (the test context) for $60 \mathrm{~min}$ to establish baseline drinking. During this session, the animals had free access to the water-filled lick tubes, and no discrete stimuli used for training were presented. After acclimation, all of the water-filled tubes were removed.

Phases 1 and 2. As previously stated, Phases 1 and 2 took place in Context A. Phase 1 training occurred on Day 2 in a 77 -min session. The subjects in all groups received eight $\mathrm{X} \rightarrow \mathrm{O}$ pairings in which the onset of the 10 -sec O occurred as the 30 -sec X terminated. The mean intertrial interval (ITI) between stimulus X onsets was $578 \pm 280 \mathrm{sec}$. The subjects in the DC condition received an additional 12 exposures of $\mathrm{O}$ interspersed with this training. The mean ITI in the latter condition was $200 \pm 120 \mathrm{sec}$ between X and unsignaled $\mathrm{O}$ onsets. Phase 2 occurred on Day 3 and consisted of the same training as Phase 1, except that the X stimulus was replaced by the A stimulus. Also, the A presentations were not followed by the outcome in the Ctrl condition.

Phase 3. On Days 4 and 5, all the subjects received four $\mathrm{O} \rightarrow \mathrm{US}$ pairings per day in Context $\mathrm{B}$. The 10 -sec $\mathrm{O}$ stimulus coterminated with the 0.5 -sec footshock. Trials occurred 10, 23, 37, and $48 \mathrm{~min}$ into the 60-min session.

Reacclimation. On Days 6 and 7, reacclimation took place in Context B for $60 \mathrm{~min}$. During these sessions, the animals had free access to the water-filled tubes and no discrete stimuli used during training were presented. On Day 6, an extra 30-min reacclimation session was given to all of the subjects. The purpose of this reacclimation session was to stabilize baseline drinking, which is usually disrupted by footshock.

Test of X. On Day 8, testing with CS X took place in Context B. After placement of the subjects in the testing context, the time required to complete the first cumulative $5 \mathrm{sec}$ of licking was recorded (pre-CS score) for each subject. Immediately following the cumula- 
tive $5 \mathrm{sec}$ of licking, CS X was presented for $15 \mathrm{~min}$, and the time it took the subject to complete an additional cumulative $5 \mathrm{sec}$ of licking (now in the presence of the CS) was recorded as our critical dependent variable (CS score). Thus, all the subjects were drinking at the time of CS onset. As is the convention in our laboratory, any subject that took more than $60 \mathrm{sec}$ to complete the first cumulative $5 \mathrm{sec}$ of licking was scheduled to be excluded from all subsequent analyses because such high pre-CS scores would indicate an unusually strong fear to the testing context. This resulted in the elimination of data from 1 subject from Group RI-DC. All the drinking latencies (both before and during the CS presentation) were converted into log (base 10) times to better approximate the within-groups normality assumption of parametric tests. An $\alpha$ level of .05 was selected as our criterion for significance.

\section{Results and Discussion}

The data are displayed in Figure 1. Group Ctrl-NoDC showed strong suppression to the target stimulus, which suggests that sensory preconditioning was observed (although there was no unpaired control in this experiment). Suppression was noticeably lower when $\mathrm{X}-\mathrm{O}$ pairings were followed by A-O pairings (Group RI-NoDC), denoting RI. Also, interspersed unsignaled outcome presentations among $\mathrm{X}-\mathrm{O}$ pairings (Group Ctrl-DC) caused low suppression, denoting a DC effect. However, the subjects that experienced both $\mathrm{A}-\mathrm{O}$ pairings and unsignaled outcome presentations (Group RI-DC) showed levels of suppression that approached that of Group Ctrl-NoDC. Thus, it appears that although RI and DC lowered conditioned suppression to the target when they were administered alone, they were more effective when they were combined. Alternatively stated, the two treatments seemed to counteract each other. The following statistical analyses support this observation.

Prior to analysis of the CS scores, the pre-CS scores were analyzed to determine whether or not the groups appreciably differed in fear of the test context. A 2 (treatment: RI vs. Ctrl) $\times 2$ (contingency: DC vs. NoDC) ANOVA did not detect any significant effects or interaction (all $p$ s $>$.19). Thus, we assumed that any group differences in suppression to the CS were not driven by differences in

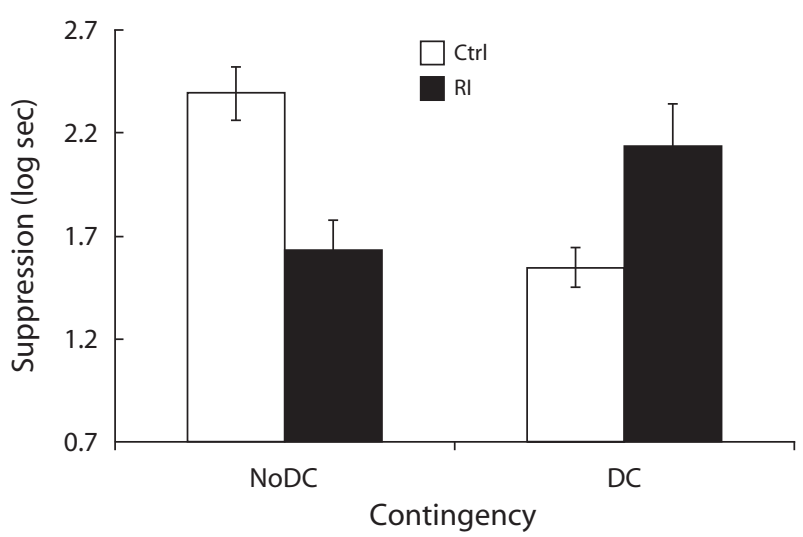

Figure 1. Mean suppression scores for the four groups in Experiment 1. Larger bars denote longer latencies to resume drinking in the presence of the CS. Thus, smaller bars suggest less fear to the target stimulus. The error bars represent the standard error for each group. generalized fear of the context. A similar ANOVA used to analyze the CS scores indicated a significant interaction between treatment and contingency $[F(1,43)=19.46]$ but no other significant effects $(p s>.27)$. Planned comparisons were conducted to determine the source of the interaction. Group Ctrl-NoDC showed more fear than Group Ctrl-DC $[F(1,43)=15.56]$. Thus, a DC effect was observed when $\mathrm{A}-\mathrm{O}$ pairings did not follow $\mathrm{X}-\mathrm{O}$ training. Also, Group Ctrl-NoDC expressed more fear than Group RI-NoDC $[F(1,43)=12.63]$, which indicates an RI effect when no unsignaled outcome presentations were interspersed with training. However, suppression in Group RI-DC was greater than that in Group Ctrl-DC $[F(1,43)=7.27]$ and Group RI-NoDC $[F(1,43)=5.35]$. Thus, when the two manipulations were combined, both of the effects were attenuated.

It is possible to explain the DC and RI effects observed here as a result of latent inhibition. Unsignaled outcome presentations could have caused latent inhibition of $\mathrm{O}$, resulting in weaker sensory preconditioning in Groups Ctrl-DC and RI-NoDC than in Group Ctrl-NoDC. However, this explanation does not account for the high level of fear observed in Group RI-DC. The subjects in this group received the largest number of $\mathrm{O}$ presentations prior to first-order conditioning and still exhibited more fear than those in Groups Ctrl-DC and RI-NoDC. Thus, the lack of fear in Groups Ctrl-DC and RI-NoDC is not likely due to simple latent inhibition. Further support for this conclusion comes from Escobar et al.'s (2001) Experiment 2, in which RI was observed in relation to three different controls. In that experiment, control subjects received A alone, $\mathrm{O}$ alone, or neither treatment in Phase 2. None of these control conditions differed from each other, suggesting that latent inhibition of $\mathrm{O}$ should not be a factor in the RI effect observed in the present studies given the large similarities in parameters and procedures between that study and the present one. We omitted the O-alone control here because we knew from Escobar et al.'s study that it would not differ from the A-alone control that we included, and because we wanted a clearer distinction between our DC manipulation and our RI manipulation.

The apparent counteraction between the RI and DC treatments could have occurred because the extensive presentations of $\mathrm{O}$ in Group RI-DC produced an increase in generalized fear. That is, the large number of $\mathrm{O}$ presentations might have caused a great expectation of $\mathrm{O}$ regardless of the test stimulus. In the present series, this possibility is somewhat dubious because the animals failed to show any differences in their fear to the test context in the pre-CS scores. In addition, in their study of outcome postexposure, Urushihara, Wheeler, and Miller (2004) administered a similarly large number of total $\mathrm{O}$ presentations (36 in comparison with our 40) and observed a profound reduction in responding to the target cue. Finally, it is unclear why an increase in generalization between stimuli would occur in Group RI-DC without any evidence of increases in responding in Group RI-NoDC or Group Ctrl-DC. In particular, one might expect to see generalization between $\mathrm{X}$ and $\mathrm{A}$ because they were both 30 -sec auditory stimuli that shared a common relation- 
ship with $\mathrm{O}$. However, the addition of A-O pairings appeared to reduce responding to $\mathrm{X}$ in Group RI-NoDC. Furthermore, a similar investigation of RI (e.g., Escobar et al., 2001) has explicitly shown an inverse relationship between responding to $\mathrm{X}$ and responding to $\mathrm{A}$.

We contend that the results indicate that RI interacts with $\mathrm{DC}$ in a way that is similar to the interaction between overshadowing and DC (Urcelay \& Miller, 2006). In this situation, RI may have been reduced because the DC treatment decreased expression of the $\mathrm{A}-\mathrm{O}$ association as well as that of the $\mathrm{X}-\mathrm{O}$ association. This explanation accounts for the attenuation of RI in Group RI-DC, but it does not account for the fact that the DC treatment was also less effective. Even if it is assumed that unsignaled outcome presentations reduced A's potential to interfere with X, the unsignaled outcome presentations should still have reduced responding to X. Instead, the results indicate that the two response-degrading treatments interacted and mutually reduced each other's effectiveness.

\section{EXPERIMENT 2}

Experiment 1 revealed a correspondence between situations in which there is competition between cues trained together (e.g., overshadowing; Urcelay \& Miller, 2006) and those in which there is competition between cues trained apart (e.g., RI; the present research). Experiment 2 was designed to further investigate whether or not interacting cues would counteract each other in situations in which one of the competing cues is not presented in compound with the target cue. In Experiment 2, RI treatment was combined with trial-massing treatment, which itself is known to attenuate conditioned responding.

Stout et al. (2003) observed an interaction between overshadowing and the trial-massing effect. Typically, an elementally trained cue elicits more conditioned responding when training trials are temporally spaced relative to when the trials are temporally massed (for reviews, see Barela, 1999; Gibbon \& Balsam, 1981). Stout et al. found that this effect is reversed when a target stimulus is trained in compound with an overshadowing stimulus. In Experiment 2 of the present study, we investigated the potential interaction between RI and trial spacing. As in Experiment 1, half of the subjects were given RI treatment (condition RI) and the other half were given a control treatment (Ctrl). Unlike in Experiment 1, the session durations and ITIs were manipulated so that trials in Phases 1 and 2 were either massed or spaced (see Table 2). All CS durations were identical to those used in Experiment 1. The trial spacing in the spaced condition in Phases 1 and 2 was the same as that used in Experiment 1, with an average of $577.5 \mathrm{sec}$ between trial onsets (including time spent in the context at the beginning and the end of the session). The average ITI in the massed condition was much shorter $(90 \mathrm{sec})$. The mean ITI for Phase 3 was the geometric mean of the average massed and spaced ITIs $(228 \mathrm{sec})$. Also, because of the high rate of responding observed in Experiment 1, the shock level was lowered from 1.0 to $0.8 \mathrm{~mA}$.

In light of the result of Experiment 1, the expected result of Experiment 2 was a bit clearer. In Experiment 1, DC
Table 2

Design of Experiment 2

\begin{tabular}{llllll}
\hline & \multicolumn{2}{c}{ Context A } & & \multicolumn{2}{c}{ Context B } \\
\cline { 2 - 3 } \cline { 6 - 6 } \multicolumn{1}{c}{ Group } & Phase 1 & Phase 2 & & Phase 3 & Test X \\
\hline Ctrl-Spaced & $8 \mathrm{X} \rightarrow \mathrm{O}$ & $8 \mathrm{~A}$ & & $8 \mathrm{O} \rightarrow \mathrm{US}$ & $\mathrm{CR}$ \\
Ctrl-Massed & $8 \mathrm{X} \rightarrow \mathrm{O}$ & $8 \mathrm{~A}$ & & $8 \mathrm{O} \rightarrow \mathrm{US}$ & $\mathrm{Cr}$ \\
RI-Spaced & $8 \mathrm{X} \rightarrow \mathrm{O}$ & $8 \mathrm{~A} \rightarrow \mathrm{O}$ & & $8 \mathrm{O} \rightarrow \mathrm{US}$ & $\mathrm{Cr}$ \\
RI-Massed & $8 \mathrm{X} \rightarrow \mathrm{O}$ & $8 \mathrm{~A} \rightarrow \mathrm{O}$ & & $8 \mathrm{O} \rightarrow \mathrm{US}$ & $?$ \\
\hline
\end{tabular}

Note-Ctrl, control; RI, retroactive interference; $\mathrm{X}$, complex tone; $\mathrm{A}$, click train; O, white noise; US, footshock; CR, strong expected conditioned response; $\mathrm{Cr}$, moderate expected conditioned response. In Phases 1 and 2, the mean ITI for the spaced condition was $577.5 \mathrm{sec}$, whereas that for the massed condition was $90 \mathrm{sec}$; in Phase 3, the mean ITI for all groups was $228 \mathrm{sec}$. The question mark denotes an uncertain outcome.

treatment interacted with RI treatment. The combination of the two produced greater conditioned suppression to the target cue than did either treatment administered alone. A similar result in Experiment 2 would be revealed by a significant interaction between RI and trial spacing. Alternatively, Experiment 2 could reveal summation of the two treatments, which would be reflected by lower conditioned suppression in Group RI-Massed than in either Group RI-Spaced or Group Ctrl-Massed. Although the latter possibility is more intuitive, the former might be considered more likely on the basis of the results of Experiment 1.

\section{Method}

\section{Subjects}

The subjects were 24 male (226-295 g) and 24 female (180$218 \mathrm{~g}$ ) experimentally naive, Sprague Dawley descended, waterdeprived rats obtained from our own breeding colony. The subjects were randomly assigned to one of four groups $(n \mathrm{~s}=12)$, counterbalanced within groups for sex. The animals were housed, handled, and water deprived as in Experiment 1.

\section{Apparatus}

The apparatus was the same as that used in Experiment 1. The stimuli were the same except for the footshock, which was $0.8 \mathrm{~mA}$.

\section{Procedure}

Acclimation. On Day 1, all the groups were acclimated to Context B (the test context) for $60 \mathrm{~min}$ to establish baseline drinking. During this session, the animals had free access to the water-filled lick tubes, and no nominal stimuli were presented. After acclimation, all of the water-filled tubes were removed.

Phases 1 and 2. As in Experiment 1, Phases 1 and 2 took place in Context A (the training context). In Phase 1, the subjects in all the groups received eight $\mathrm{X} \rightarrow \mathrm{O}$ pairings in which the onset of the 10 -sec $\mathrm{O}$ occurred as the 30 -sec $\mathrm{X}$ terminated. For the subjects in the spaced condition, these pairings occurred $5,19,24,36,43,54.5$, 59.5 , and $69.5 \mathrm{~min}$ into the $77-\mathrm{min}$ session. For the subjects in the massed condition, the pairing occurred 47, 144, 224, 337, 402, 490, 556 , and $650 \mathrm{sec}$ into a 12 -min session. Phase 2 occurred on Day 3 and consisted of the same training as Phase 1, except that the X stimulus was replaced by the A stimulus and the A presentations were not followed by the outcome in the control condition. Thus, the ITIs for the massed and spaced conditions were the same as in Phase 1.

Phase 3. On Days 4 and 5, all the subjects received four $\mathrm{O} \rightarrow \mathrm{US}$ pairings per day in Context B. The 10 -sec $\mathrm{O}$ stimulus coterminated with the 0.5 -sec footshock. The average time between footshocks was $228 \mathrm{sec}$ (the geometric mean of 90 and $577.5 \mathrm{sec}$ ). Trials occurred 3, 7, 10, and 14 min into each 15.2-min session.

Reacclimation and testing. On Days 6-8, reacclimation, testing, and data transformation were conducted as they were in Ex- 
periment 1. All the subjects completed their first cumulative $5 \mathrm{sec}$ of licking within $60 \mathrm{sec}$; consequently, no subjects were eliminated on the basis of that criterion.

\section{Results and Discussion}

The results of Experiment 2 are displayed in Figure 2. The subjects in Group Ctrl-Spaced expressed the most fear of the CS. As in Experiment 1, RI was observed when $\mathrm{A}-\mathrm{O}$ pairings followed $\mathrm{X}-\mathrm{O}$ pairings in long experimental sessions (Group RI-Spaced). The subjects that experienced temporally massed $\mathrm{X}-\mathrm{O}$ pairings with no A-O exposure (Group Ctrl-Massed) showed the weakest level of suppression. When the two treatments were combined (Group RI-Massed), conditioned suppression was greater than that observed in Group Ctrl-Massed but not less than that observed in Group RI-Spaced. These observations are supported by the following statistical analyses.

Before any of the CS scores were analyzed, the pre-CS scores were analyzed with a 2 (treatment: RI vs. Ctrl) $\times 2$ (trial spacing: spaced vs. massed) ANOVA. This analysis revealed no significant main effects or interaction ( $p \mathrm{~s}>$ .29). A similar analysis of the CS scores showed a main effect of trial spacing $[F(1,44)=21.93]$ and, importantly, an interaction between treatment and trial spacing $[F(1,44)=$ 12.13], but no main effect of treatment $(p>.80)$. Planned comparisons were conducted to determine the source of the interaction. A comparison of Groups RI-Spaced and Ctrl-Spaced showed that RI was apparent when the trials were sufficiently spaced $[F(1,44)=6.99]$. Also, Group Ctrl-Spaced responded more than Group Ctrl-Massed, indicating that massed training reduced conditioned suppression to $\mathrm{X}$ when $\mathrm{X}-\mathrm{O}$ training was not followed by A-O training $[F(1,44)=33.35]$. In the group for which the two response-degrading treatments were combined (RI-Massed), suppression was greater than that observed in Group Ctrl-Massed $[F(1,44)=5.21]$. However, conditioned fear in Groups RI-Massed and RI-Spaced did not differ significantly $[F(1,44)=0.72, p>.40]$. Thus, there was an interaction between RI and trial-massing treat-

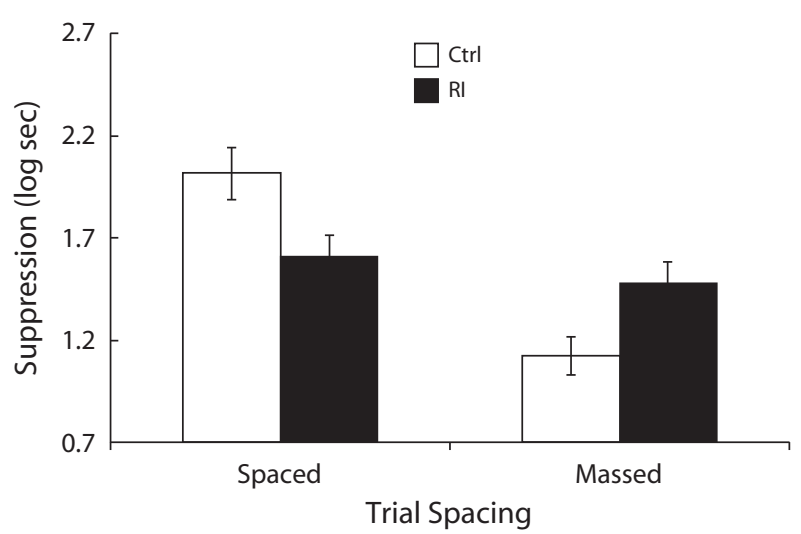

Figure 2. Mean suppression scores for the four groups in Experiment 2. Larger bars denote longer latencies to resume drinking in the presence of the CS. Thus, smaller bars suggest less fear to the target stimulus. The error bars represent the standard error for each group. ments, but the conditioned fear produced by combining the two treatments was not significantly stronger than the fear observed in Group RI-Spaced.

There are at least two primitive interpretations of the results of Experiment 2. One is that RI attenuated the response-degrading effects of trial massing but trial massing did not have a similar effect on RI. The level of suppression observed in Group RI-Massed was greater than that in Group Ctrl-Massed (which indicates an attenuation of the trial-massing effect) but was not greater than that in Group RI-Spaced. This account is supported by the analyses employed here, but it is not the only way to interpret the results of Experiment 2. Another potential explanation is that the RI treatment only partially attenuated the effect of trial massing. The RI effect observed in Experiment 2 was less robust than the trial-massing effect, as is suggested by the presence of a main effect of trial spacing but not of interference treatment. Therefore, the symmetrical counteraction observed in Experiment 1 might be absent here because the independent effects were not of equal strength: The trial-massing manipulation might have been sufficient to attenuate RI, but the RI effect might not have been sufficiently strong to completely reduce the trial-massing effect. Although the two treatments did not completely counteract each other as in Experiment 1, there was clearly an interaction, and no suggestion of summation.

\section{GENERAL DISCUSSION}

The results presented here show some correspondence between situations in which there is competition between cues trained together (e.g., overshadowing) and situations in which there is competition between cues trained apart (e.g., RI). In Experiment 1, RI attenuated the DC effect and vice versa. This result mirrors the results of Urcelay and Miller (2006), who found that DC treatment and overshadowing treatment reciprocally counteract one another. In Experiment 2, RI treatment did appear to attenuate the effect of trial massing, but there was not a symmetrical counteraction. The subjects that experienced the combined treatments exhibited more conditioned suppression than did those that received only massed trials, and conditioned suppression approximately equivalent to that of those that received only RI treatment. Thus, the present results do not show complete correspondence with the findings of Stout et al. (2003), who showed that overshadowing treatment and trial massing counteract each other. Even so, there was clearly an interaction between the two variables and no indication that the two effects summated.

At the present time, no single theory of learning can account for the results presented here. Most contemporary theories account for competition between cues trained together and do not predict that RI would occur between cues trained apart (see, e.g., Gallistel \& Gibbon, 2000; Mackintosh, 1975; Miller \& Matzel, 1988; Pearce \& Hall, 1980; Rescorla \& Wagner, 1972; Wagner, 1981). Even theories that can account for backward blocking (i.e., AX-O training followed by $\mathrm{A}-\mathrm{O}$ training) rely on the formation of a within-compound association and would not predict the 
RI effect observed in Experiments 1 and 2 because $X$ and A were never trained together (e.g., Dickinson \& Burke, 1996; Miller \& Matzel, 1988; Van Hamme \& Wasserman, 1994). Miller and Escobar (2002) suggested a framework that could account for RI by combining a theory that accounts for interference between cues trained apart with Miller and Matzel's comparator account of competition between cues trained together. Although their theory does not completely explain the results observed here, it does account for much of the data.

To explain competition between cues trained together, Miller and Escobar (2002) appealed to Miller and Matzel's (1988) comparator hypothesis (see also Denniston et al., 2001). According to this theory, competition between cues trained together occurs when a target cue is tested, and it is mediated by the current associative status of any cue that has a direct association with the target cue and the outcome (called a comparator stimulus). Responding to the target cue is directly related to the strength of its association with the outcome (Link 1 in the framework of the comparator hypothesis). At the same time, responding to the target is reduced by the strength of the within-compound association between the target cue and the comparator stimulus (Link 2) and the strength of the association between the comparator stimulus and the outcome (Link 3). Specifically, the product of Links 2 and 3 reduces the expression of Link 1.

The comparator mechanism can account for some of the results observed in Experiments 1 and 2 if it is assumed that the context of training can act as a comparator stimulus. For example, in Experiment 1 the subjects in the control condition received $\mathrm{X}-\mathrm{O}$ pairings with no RI treatment. According to the comparator hypothesis, expression of the $\mathrm{X}-\mathrm{O}$ association at test will be reduced if the context has an exceptionally strong association with $\mathrm{X}$ and/or O. In Group Ctrl-DC, the X-O pairings were accompanied by interspersed, unsignaled $\mathrm{O}$ presentations, which should have augmented the strength of the context-O association (Link 3 according to the comparator hypothesis). Thus, the comparator hypothesis predicts an effect of DC treatment in Experiment 1 because there was a strong association between $\mathrm{O}$ and the training context. ${ }^{1}$ This account of DC has been supported by similar studies from our laboratory that indicate that subjects can recover from the effect of DC if the training context is extinguished after target-stimulus training (e.g., Urcelay \& Miller, 2006; Witnauer \& Miller, 2006). Thus, DC appears to be dependent on the associative status of the context at test. Similarly, the trial-massing effect observed in Experiment 2 can be explained by assuming that the training context can act as a comparator stimulus. In this case, both the context-X (Link 2) and the context-O (Link 3) associations are strong in Group Ctrl-Massed because there is little extinction of the context between trials in the massed condition relative to the spaced condition. As with DC, context extinction after massed training trials alleviates the trial-massing effect (Stout et al., 2003). Although comparator theory does effectively explain DC and trialmassing effects, it fails to account for RI.

In order to explain competition between cues trained apart, such as the RI effect observed in the present stud- ies, Miller and Escobar (2002) posited that interference can occur between two cues that are not directly associated to each other as a result of a priming mechanism that operates independent of the comparator mechanism. For interference to be strong, the interfering cue must share similar attributes with the target cue, including their associations with a common outcome. (However, if the two associations are not discriminable, enhancement will be observed because the nontarget trials will essentially be more target training trials.) Also, the interfering cue must be primed when the target stimulus is tested. Priming can be achieved through presentation of an associate of the interfering stimulus or through recency, which leads to stronger expression of more recent learning. Applied to the RI effect observed here, the $\mathrm{A}-\mathrm{O}$ association is primed because it has been trained more recently than the target association. Furthermore, A and X share a similar association with the outcome, which also facilitates interference. Therefore, when $\mathrm{X}$ is tested, the expression of the $\mathrm{X}-\mathrm{O}$ association is disrupted by the primed $\mathrm{A}-\mathrm{O}$ association (see Anderson, Bjork, \& Bjork, 2000, for an example of this sort of impaired retrieval in the human learning literature).

Miller and Escobar's (2002) dual-process model can account for the individual response-degrading effects observed in Experiments 1 and 2 (i.e., DC, trial massing, and RI). However, a straightforward application of Miller and Escobar's model does not explain the counteraction observed in Experiment 1 when two response-degrading treatments were combined. Specifically, the model would fail to predict that the presence of unsignaled outcomes in Phase 2 would reduce RI. According to the model, the DC effect relies on the comparator process and the RI effect relies on the priming process. Because the two processes operate independently in the model, there is no reason to expect that a comparator process involving the context and A would modulate the priming process involving $\mathrm{A}$ and $\mathrm{X}$. In an attempt to accommodate the present results, one could assume that the priming process and comparator process are not independent, but such an assumption would violate one of the primitives of the model. Furthermore, making such a fundamental alteration of the model may have an unforeseen consequence for established predictions.

More important than the specific theoretical implications, the two experiments presented here converge with other studies in which counteractions were found between select treatments that normally reduce responding to a CS. Generally, most theories would predict that two responsedegrading treatments would summate when combined, resulting in even weaker responding. The present study contributes to the aforementioned body of results by presenting two situations in which this is not the case. It is important to note, however, that response-degrading treatments do not always counteract each other. For example, Nakajima et al. (1999) observed summation of latent inhibition and overshadowing treatments in a conditioned taste aversion preparation, failing to replicate the counteraction observed by Blaisdell et al. (1998) and replicated by Ishii (1999). Along the lines of Nakajima et al., an un- 
published experiment from our laboratory strongly suggests that latent inhibition and RI treatments summate. In that experiment, preexposure of the target cue prior to RI treatment resulted in very weak responding to the target cue. Although the data suffer from a statistical ambiguity that prevents us from determining whether or not summation occurred, there was certainly no counteraction effect. Indeed, even in the results of the present Experiment 2, the interaction between trial massing and RI did not produce a symmetrical counteraction of the two effects. It is clear that the variables that determine how different competing stimuli interact call for further study (e.g., Urushihara \& Miller, 2006b).

Although Miller and Escobar (2002) proposed two separate mechanisms to explain cue competition effects that occur when cues are trained together and cue interference effects that occur when cues are trained apart, the results of the experiments presented here and elsewhere show some intriguing empirical similarities between the two types of cue interaction. Broadly speaking, the results of Experiments 1 and 2 indicate that the counterintuitive interactions between the response-degrading effects previously observed by Miller and colleagues, among others (e.g., Ishii, 1999; Loy \& Hall, 2002; Maier, Jackson, \& Tomie, 1987; Westbrook et al., 1983), are not unique to situations in which compound training occurs. Instead, these counteraction effects appear to arise more generally in situations in which cues interact with each other independently of whether they have been trained together or apart. Future studies should focus on the parameters that determine when counteraction occurs.

\section{AUTHOR NOTE}

NIMH Grant 33881 provided support for this research. We thank Jim Esposito for his technical assistance and Jeffrey C. Amundson, Jonah Grossman, David Guez, Rachael Hessner, Olga Lipatova, Alyssa Orinstein, Olga Perelmuter, Gonzalo Urcelay, Kouji Urushihara, and Jim Witnauer for comments on an earlier version of the manuscript. Correspondence concerning this article should be addressed to R. R. Miller, Department of Psychology, SUNY Binghamton, Binghamton, NY 13902-6000 (e-mail: rmiller@binghamton.edu).

\section{REFERENCES}

Anderson, M. C., BJork, E. L., \& BJork, R. A. (2000). Retrievalinduced forgetting: Evidence for a recall-specific mechanism. Psychonomic Bulletin \& Review, 7, 522-530.

BARELA, P. B. (1999). Theoretical mechanisms underlying the trialspacing effect in Pavlovian fear conditioning. Journal of Experimental Psychology: Animal Behavior Processes, 25, 177-193.

BLAISDELl, A. P., BRISTOL, A. S., GUNTHER, L. M., \& Miller, R. R. (1998). Overshadowing and latent inhibition counteract each other: Support for the comparator hypothesis. Journal of Experimental Psychology: Animal Behavior Processes, 24,335-351.

Denniston, J. C., Savastano, H. I., \& Miller, R. R. (2001). The extended comparator hypothesis: Learning by contiguity, responding by relative strength. In R. R. Mower \& S. B. Klein (Eds.), Handbook of contemporary learning theories (pp. 65-117). Mahwah, NJ: Erlbaum.

Dickinson, A., \& BuRKe, J. (1996). Within-compound associations mediate the retrospective revaluation of causality judgements. Quarterly Journal of Experimental Psychology, 49B, 60-80.

Escobar, M., Matute, H., \& Miller, R. R. (2001). Cues trained apart compete for behavioral control in rats: Convergence with the asso- ciative interference literature. Journal of Experimental Psychology: General, 130, 97-115.

GALlistel, C. R., \& GibBon, J. (2000). Time, rate, and conditioning. Psychological Review, 107, 289-344.

GiBBON, J., \& BALSAM, P. (1981). Spreading association in time. In C. M. Locurto, H. S. Terrace, \& J. Gibbon (Eds.), Autoshaping and conditioning theory (pp. 219-253). New York: Academic Press.

Gunther, L. M., \& Miller, R. R. (2000). Prevention of the degradedcontingency effect by signalling training trials. Quarterly Journal of Experimental Psychology, 53B, 97-119.

IsHII, K. (1999). Attenuation of latent inhibition after compound conditioning. Japanese Psychological Research, 41, 102-111.

Kasprow, W. J., Schachtman, T. R., \& Miller, R. R. (1987). The comparator hypothesis of conditioned response generation: Manifest conditioned excitation and inhibition as a function of relative excitatory strengths of CS and conditioning context at the time of testing. Journal of Experimental Psychology: Animal Behavior Processes, 13,395-406.

Lovibond, P. F., Preston, G. C., \& Mackintosh, N. J. (1984). Context specificity of conditioning, extinction, and latent inhibition. Journal of Experimental Psychology: Animal Behavior Processes, 10, $\overline{360-375}$.

LOY, I., \& HALL, G. (2002). Taste aversion after ingestion of lithium chloride: An associative analysis. Quarterly Journal of Experimental Psychology, 55B, 365-380.

LuBOW, R. E. (1989). Latent inhibition and conditioned attention theory. New York: Cambridge University Press.

Lubow, R. E., \& GewirTZ, J. C. (1995). Latent inhibition in humans: Data, theory, and implications for schizophrenia. Psychological Bulletin, 117, 87-103.

LUBOW, R. E., \& MoOre, A. U. (1959). Latent inhibition: The effect of nonreinforced pre-exposure to the conditional stimulus. Journal of Comparative \& Physiological Psychology, 52, 415-419.

MACKINTOSH, N. J. (1975). A theory of attention: Variations in the associability of stimuli with reinforcement. Psychological Review, 82, 276-298.

MAIER, S. F., JACKSON, R. L., \& TomiE, A. (1987). Potentiation, overshadowing, and prior exposure to inescapable shock. Journal of Experimental Psychology: Animal Behavior Processes, 13, 260-270.

MilLER, R. R., \& Escobar, M. (2002). Associative interference between cues and between outcomes presented together and presented apart: An integration. Behavioural Processes, 57, 163-185.

Miller, R. R., \& MATUTE, H. (1996). Biological significance in forward and backward blocking: Resolution of a discrepancy between animal conditioning and human causal judgment. Journal of Experimental Psychology: General, 125, 370-386.

MiLLER, R. R., \& MATZEL, L. D. (1988). The comparator hypothesis: A response rule for the expression of associations. In G. H. Bower (Ed.), The psychology of learning and motivation: Advances in research and theory (Vol. 22, pp. 51-92). San Diego: Academic Press.

NAKAJIMA, S., KA, H., \& IMADA, H. (1999). Summation of overshadowing and latent inhibition in rats' conditioned taste aversion: Scapegoat technique works for familiar meals. Appetite, 33, 299-307.

NaKaJima, S., \& Nagaishi, T. (2005). Summation of latent inhibition and overshadowing in a generalized bait shyness paradigm of rats. Behavioural Processes, 69, 369-377.

PAVLOV, I. P. (1927). Conditioned reflexes (V. Anrep, Trans.). New York: Dover.

Pearce, J. M., \& Hall, G. (1980). A model for Pavlovian learning: Variations in the effectiveness of conditioned but not of unconditioned stimuli. Psychological Review, 87, 532-552.

ResCORLA, R. A. (1968). Probability of shock in the presence and absence of CS in fear conditioning. Journal of Comparative \& Physiological Psychology, 66, 1-5.

RESCORLA, R. A., \& WAGNER, A. R. (1972). A theory of Pavlovian conditioning: Variations in the effectiveness of reinforcement and non-reinforcement. In A. H. Black \& W. F. Prokasy (Eds.), Classical conditioning II: Current research and theory (pp. 64-99). New York: Appleton-Century-Crofts

Stout, S. C., Chang, R., \& Miller, R. R. (2003). Trial spacing is a determinant of cue interaction. Journal of Experimental Psychology: Animal Behavior Processes, 29, 23-38

URCELAY, G. P., \& MilleR, R. R. (2006). Counteraction between over- 
shadowing and degraded contingency treatments: Support for the extended comparator hypothesis. Journal of Experimental Psychology: Animal Behavior Processes, 32, 21-32.

URUShiHARA, K., \& MilleR, R. R. (2006a). Overshadowing and the outcome-alone exposure effect counteract each other. Journal of Experimental Psychology: Animal Behavior Processes, 32, 253-270.

URUShiHARA, K., \& Miller, R. R. (2006b). Partial reinforcement and CS duration effects counteract overshadowing in select situations. Manuscript submitted for publication.

Urushihara, K., Stout, S. C., \& Miller, R. R. (2004). The basic laws of conditioning differ for elemental cues and cues trained in compound. Psychological Science, 15, 268-271.

Urushihara, K., Wheeler, D. S., \& Miller, R. R. (2004). Outcome pre- and postexposure effects: Retention interval interacts with primacy and recency. Journal of Experimental Psychology: Animal Behavior Processes, 30, 283-298.

VAN HAMME, L. J., \& WASSERMAN, E. A. (1994). Cue competition in causality judgments: The role of nonpresentation of compound stimulus elements. Learning \& Motivation, 25, 127-151.

WAGNER, A. R. (1981). SOP: A model of automatic memory processing in animal behavior. In N. E. Spear \& R. R. Miller (Eds.), Information processing in animals: Memory mechanisms (pp. 5-47). Hillsdale, NJ: Erlbaum.

Westbrook, R. F., Homewood, J., Horn, K., \& Clarke, J. C. (1983). Flavour-odour compound conditioning: Odour-potentiation and flavour-attenuation. Quarterly Journal of Experimental Psychology, 35B, 13-33.

Witnauer, J. E., \& Miller, R. R. (2006). Degraded contingency revisited: Posttraining extinction of a cover stimulus attenuates a target cue's behavioral control. Manuscript submitted for publication.

\section{NOTE}

1. The training context, not the test context, acts as an effective comparator stimulus for the target here because it is associated with the target stimulus and the outcome. The test context should have little impact on responding to the target, assuming that the potential for summation is minimized, as was the case here (see, e.g., Kasprow, Schachtman, \& Miller, 1987).

(Manuscript received June 16, 2006; revision accepted for publication November 13, 2006.) 